\title{
Redo-urethroplasty for the management of recurrent urethral strictures in males: a systematic review
}

\author{
Sara Jasionowska ${ }^{1,2} \cdot$ Oliver Brunckhorst $^{1,2} \cdot$ Rowland W. Rees $^{3} \cdot$ Asif Muneer $^{4} \cdot$ Kamran Ahmed $^{1,2}$
}

Received: 12 December 2018 / Accepted: 26 February 2019 / Published online: 15 March 2019

(c) The Author(s) 2019

\begin{abstract}
Purpose Redo-urethroplasty is a challenge for any genitourethral surgeon, with a number of techniques previously described. This systematic review aims to identify the surgical techniques described in the literature and evaluate the evidence for their effectiveness in managing recurrent urethral strictures.

Materials and methods A systematic review of the MEDLINE and EMBASE databases from 1945 to July 2018 was performed and the urethroplasty procedures were classified according to the site and surgical technique. Primary outcomes included success rates measured via re-stricture rates and the post-op maximum urinary flow rate. Secondary outcomes included complication rates and patient-reported quality of life.

Results A total of 39 identified studies met the inclusion criteria. Twenty-two studies described the use of excision and primary anastomotic urethroplasty with success rates showing wide variability (58-100\%). Success rates reported according to the site of the stricture also varied: bulbar (58-100\%) and posterior (69-100\%) recurrent strictures. One-stage substitution urethroplasty was described in 25 studies with success rates of $18-100 \%$, with the best outcomes reported for bulbar (58-100\%) and hypospadias-related (78.6-82\%) strictures. Two-stage substitution urethroplasty was described in 12 studies with the success rates of 20-100\%, with the best evidence related to hypospadias-related and posterior urethral strictures. The buccal mucosa graft was the graft source with the best evidence for substitution urethroplasty (18-100\%).

Conclusions Trends of effectiveness were identified for redo-urethroplasty modalities in different locations. However, the current levels of evidence are limited to small observational studies, highlighting the need for further larger prospective data to evaluate different techniques used for recurrent urethral strictures.
\end{abstract}

Keywords Urethral stricture $\cdot$ Redo-urethroplasty $\cdot$ Failed urethroplasty $\cdot$ Repeat urethroplasty

\section{Introduction}

Electronic supplementary material The online version of this article (https://doi.org/10.1007/s00345-019-02709-7) contains supplementary material, which is available to authorized users.

Kamran Ahmed

kamran.ahmed@kcl.ac.uk

1 MRC Centre for Transplantation, Guy's Hospital, King's College London, London, UK

2 Department of Urology, King's College Hospital, London, UK

3 Urology Department, University Hospital Southampton, NHS Foundation Trust, Southampton, UK

4 Department of Urology, NIHR Biomedical Research Centre, University College Hospital, University College London Hospitals NHS Foundation Trust, London, UK
Open reconstructive urethroplasty offers a cost-effective treatment modality for urethral strictures with excellent early success rates of $79-95 \%$ [1]. However, long-term results demonstrate that $14-42 \%$ of patients require additional treatment for recurrent strictures after primary surgical reconstruction [2]. Despite this, there are few standardised guidelines for the treatment of urethral stricture recurrence following urethroplasty, with practice varying widely between urologists [3].

Redo-urethroplasty and direct vision internal urethrotomy (DVIU) are the established techniques. DVIU remains the most commonly utilised initial method, as it offers a minimally invasive approach with fewer technical challenges, and allows endoscopic assessment of the recurrent stricture. Whilst identified as a valuable therapeutic option for short 
$(<1 \mathrm{~cm})$ or bulbar recurrent strictures, high failure rates of up to $100 \%$ and complications such as bleeding and infection limit its use to older men, those unwilling to undergo an open reconstruction or patients with multiple comorbidities [4, 5]. Additionally, repeated endoscopic treatment can result in a chronic urethral stricture, requiring redo DVIU and self-dilatation at regular intervals throughout a man's lifetime [6]. On the contrary, reported success rates of redourethroplasty range between 67 and $92 \%$ [1].

There is considerable variation in the treatment of recurrent urethral strictures from different groups and organisations [7]. Recurrent strictures remain challenging for reconstructive surgeons, as they are often more complex, associated with extensive scarring and poor tissue vascularity. Data suggest that prior endoscopic treatment is an independent risk factor for failure after urethroplasty [8]. Additionally, numerous urethroplasty techniques have been described in the literature, but there is a paucity of guidelines with regard the optimal choice of procedure for recurrent strictures, based on the stricture aetiology and location. Therefore, this systematic review aims to:

1. Identify the current techniques described in the literature for redo-urethroplasty for recurrent urethral strictures.

2. Evaluate the current evidence base for the effectiveness of different redo-urethroplasty techniques via re-stricture and complication rates.

3. Discuss current follow-up methods following redo-urethroplasty.

4. Suggest treatment options based on the current evidence for recurrent urethral strictures at different locations and of different aetiologies.

\section{Materials and methods}

This systematic review was conducted according to the Preferred Reporting Items for Systematic Reviews and MetaAnalyses (PRISMA) guidelines [9]. Additionally, this study was prospectively registered on the PROSPERO database (Registration Number CRD42018088874).

\section{Study eligibility criteria}

Original research articles including randomised controlled trials, case series and cohort studies as well as conference abstracts with sufficient data that described techniques and outcomes of redo-urethroplasty were included in this study.

Abstracts with insufficient information, non-English articles, case reports, paediatric studies or studies utilising female subjects were excluded. Additionally, only patients with at least one failed urethroplasty previously and having undergone a redo-urethroplasty were eligible for analysis.

\section{Information sources and search}

Studies were identified by searching MEDLINE and EMBASE databases from 1945-July 2018. No restrictions with regard to publication status were imposed. The last search was performed on the 22.07.2018. Search terms included a combination of "urethroplasty" and "redo" or "reoperative", which identified the majority of the articles. These results were combined with "hypospadias", "urethral", "panurethral", "treatment failure", "urethra surgery" and technique" to supplement the identified studies. A reference review of identified articles was subsequently carried out. Ongoing clinical trials were searched for grey literature at http://www.clinicaltrials.gov with authors of potentially relevant studies contacted for preliminary or unpublished results for inclusion in review.

\section{Study selection}

The search and study selection were performed independently by two reviewers (SJ and OB) with any discrepancies discussed. The advice of the third reviewer was sought if these could not be resolved. Studies that were identified using the search terms were assessed for further evaluation through abstract review once duplicates were removed. Subsequently, a full text review allowed exclusion of the irrelevant studies.

\section{Data collection and data items}

Data were extracted from all studies onto a pre-defined extraction sheet including the following: author, publication year, surgical technique, number of patients, age of patient, location and length of the stricture, previous treatment, and aetiology of the stricture.

Primary outcome measures to assess the effectiveness specific for each surgical technique included success rate measured as re-stricture rate and post-op maximum urinary flow rate $\left(Q_{\max }\right)$. Secondary measures included complication rates, post-operative patient-reported quality of life (assessed through questionnaires and patient-reported symptoms) and follow-up method.

This process was performed by two researchers independently (SJ and $\mathrm{OB}$ ) and any discrepancies were addressed. Quality Appraisal of Case Series Studies Checklist [10] was used to assess bias as the case series and case-control studies were the only type of papers identified in this review. This is a 20-item checklist developed and validated by the Institute of Health Economics to be used as a risk of bias assessment tool. 


\section{Results}

\section{Study selection}

A total of 4800 potentially relevant studies were identified. Abstract review and removal of duplications allowed for exclusion of 4661 articles. After review of full-texts, 103 studies were excluded from the analysis. Three articles were added after reference review. The final analysis was conducted on 39 articles (Fig. 1). Two ongoing clinical trials were identified with no data available for inclusion in review after authors were contacted.

\section{Study characteristics and results synthesis}

Articles included in the review consisted of case series with both retrospective and prospective data analyses. The results were tabulated and the studies were grouped according to the surgical technique used and stricture location. Separate consideration was also given to strictures with a background of hypospadias and trauma. Data extracted from the studies were categorised into the following headings: the success rates of different redo-urethroplasty techniques, the success rates of different sites of stricture, complication rates and follow-up methods following redo-urethroplasty.

\section{Types of procedures and their outcomes}

\section{Anastomotic urethroplasty (AU)}

Twenty-two studies described the use of anastomotic end-toend urethroplasty in 893 patients (Table 1). AU was used to treat anterior strictures in $32 \%(n=7)$ [11, 14, 17, 18, 20, 25, 29], posterior strictures in $45 \%(n=10)[13,15,19,23,26$, $28-30,45,46]$ and mixed bulbo-membranous strictures in $14 \%(n=3)[15,27,29]$ of the studies which were reviewed. Five studies $(n=5)$ [12, 16, 21, 22, 24] did not provide information on the location of the stricture. Additionally, over half $(n=12)$ of the studies did not report the mean length of the urethral stricture treated, with only three studies [17, $27,45]$ reporting the mean stricture length specifically for the patients who underwent the anastomotic procedure as $2.1 \mathrm{~cm}$ for bulbar, $2.8 \mathrm{~cm}$ for membranous and $4.2 \mathrm{~cm}$ for bulbo-membranous strictures. The mean follow-up ranged
Fig. 1 PRISMA diagram for study selection
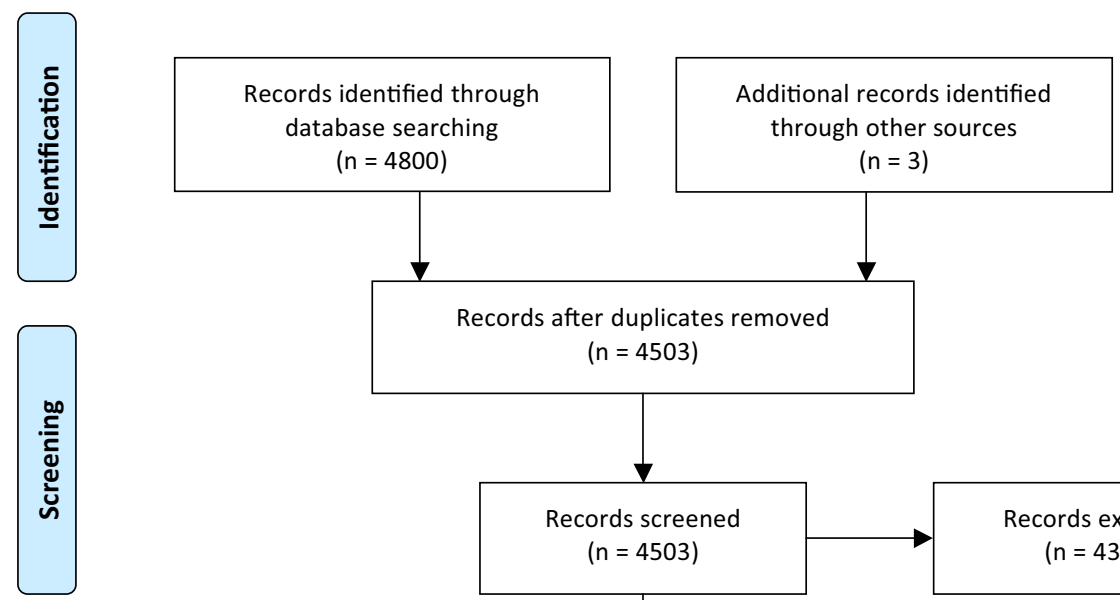

Records after duplicates removed ( $n=4503$ )
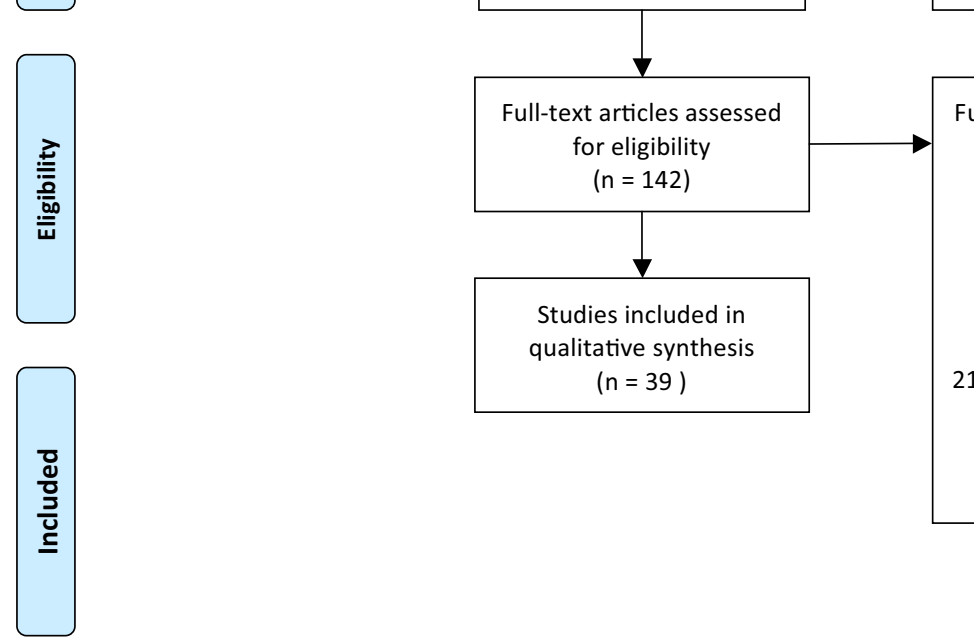

Records excluded $(n=4360)$

Full-text articles excluded, with reasons ( $n=103$ ) Reasons:

54: paediatric cohorts 15: primary cases 2: single case reports 4: non-english papers 21: describe complications not success rates

7: describe different procedures 
from 4 to 70 months in the studies reviewed. Six studies did not report the exact number of patients undergoing AU.

Success rates were reported in 19 studies and ranged from 58 to $100 \%$ (Table 1). The most commonly used definition for procedural failure was the need for any instrumentation as reported in $32 \%(n=7)$ [21, 25-28, 30, 45] of studies. The need for surgical intervention reported in $14 \%(n=3)$ $[12,14,19]$ and radiological abnormality reported in $9 \%$

Table 1 Articles describing anastomotic urethroplasty

\begin{tabular}{|c|c|c|c|c|c|c|}
\hline $\begin{array}{l}\text { Article first author, } \\
\text { publication date }\end{array}$ & No. of patients & Stricture site & Success rate & Failure definition & $\begin{array}{l}\text { Mean } \\
\text { follow-up } \\
\text { (months) }\end{array}$ & Mean length $(\mathrm{cm})$ \\
\hline $\begin{array}{l}\text { Ekerhult et al., } 2016 \\
{[14]^{\mathrm{a}}}\end{array}$ & 20 & Bulbar & $58 \%$ bulbar & $\begin{array}{l}\text { Need for surgical } \\
\text { instrumentation }\end{array}$ & Bulbar 70 & Bulbar 2 \\
\hline $\begin{array}{l}\text { Bhagat et al., } 2011 \\
{[15]^{\mathrm{a}}}\end{array}$ & 40 & $\begin{array}{l}\text { Bulbo-membranous/ } \\
\text { membranous/pros- } \\
\text { tato-membranous }\end{array}$ & N/D & $\begin{array}{l}\text { Maximum urinary } \\
\text { flow }<15 \mathrm{ml} / \mathrm{s}\end{array}$ & 60 & 3.7 \\
\hline Gupta et al., 2008 [13] & 52 & Posterior & $96.20 \%$ & $\begin{array}{l}\text { Maximum urinary } \\
\text { flow }<10 \mathrm{ml} / \mathrm{s}\end{array}$ & 54 & N/D \\
\hline $\begin{array}{l}\text { Levine et al., } 2014 \\
\text { [16] }^{\mathrm{a}}\end{array}$ & 8 & N/D & $88 \%$ & Urethral patency $<16 \mathrm{Fr}$ & 49 & 4.9 \\
\hline $\begin{array}{l}\text { Blaschko et al., } 2012 \\
{[12]^{\mathrm{a}}}\end{array}$ & 54 & N/D & $88 \%$ & $\begin{array}{l}\text { Need for surgical } \\
\text { intervention or more } \\
\text { than one endoscopic } \\
\text { treatment }\end{array}$ & 55 & 4.4 \\
\hline Siegel et al., 2015 [17] & 19 & Bulbar & $95 \%$ & N/D & 30.1 & 2.1 \\
\hline $\begin{array}{l}\text { Barbagli et al., } 1996 \\
\text { [11] }^{\mathrm{a}}\end{array}$ & 2 & Anterior & $100 \%$ & $\mathrm{~N} / \mathrm{D}$ & 57 & N/D \\
\hline Morey et al., $1997[18]^{a}$ & N/D & Bulbar & $100 \%$ & $\mathrm{~N} / \mathrm{D}$ & 12 & N/D \\
\hline $\begin{array}{l}\text { Wadhwa et al., } 1998 \\
{[19]^{\mathrm{a}}}\end{array}$ & 14 & Posterior & $78.57 \%$ & $\begin{array}{r}\text { Need for surgical } \\
\text { instrumentation }\end{array}$ & 4 & 2 \\
\hline $\begin{array}{l}\text { Joseph et al., } 2002 \\
{[20]^{\mathrm{a}}}\end{array}$ & $\mathrm{N} / \mathrm{D}$ & Bulbar/penile & $100 \%$ & N/D & 60 & N/D \\
\hline Shau et al., 2015 [21 $^{\mathrm{a}}$ & $\mathrm{N} / \mathrm{D}$ & N/D & $80 \%$ & $\begin{array}{l}\text { Need for any instru- } \\
\text { mentation }\end{array}$ & 42 & 2.7 \\
\hline Jakse et al., 1996 [22] & 52 & N/D & $90.40 \%$ & $\mathrm{~N} / \mathrm{D}$ & 45 & N/D \\
\hline Orabi et al., $2008[23]^{\mathrm{a}}$ & 25 & Posterior & $97 \%$ & $\mathrm{~N} / \mathrm{D}$ & $\mathrm{N} / \mathrm{D}$ & N/D \\
\hline $\begin{array}{l}\text { Imbeault et al., } 2014 \\
{[24]^{\mathrm{a}}}\end{array}$ & N/D & N/D & N/D & $\begin{array}{l}\text { Radiological abnor- } \\
\text { mality }\end{array}$ & 25 & N/D \\
\hline $\begin{array}{l}\text { Cavalcanti et al., } 2012 \\
{[25]^{\mathrm{a}}}\end{array}$ & 6 & Bulbar & $81.80 \%$ & $\begin{array}{l}\text { Need for any instru- } \\
\text { mentation or } \\
Q_{\max }<15 \mathrm{ml} / \mathrm{s}\end{array}$ & 30.8 & 2.8 \\
\hline $\begin{array}{l}\text { Pardeshi et al., } 2016 \\
\text { [26] }\end{array}$ & 21 & Posterior & $95.20 \%$ & $\begin{array}{l}\text { Need for instrumenta- } \\
\text { tion }\end{array}$ & N/D & N/D \\
\hline $\begin{array}{l}\text { Kulkarni et al., } 2015 \\
\text { [27] }\end{array}$ & 15 & Bulbo-membranous & $93.30 \%$ & $\begin{array}{l}\text { Need for any instru- } \\
\text { mentation }\end{array}$ & 18 & 4.2 \\
\hline $\begin{array}{l}\text { Patrascoiu et al., } 2012 \\
\text { [28] }\end{array}$ & 16 & Posterior & $68.70 \%$ & $\begin{array}{l}\text { Need for instrumenta- } \\
\text { tion or maximum } \\
\text { flow }<18 \mathrm{ml} / \mathrm{s}\end{array}$ & 38 & N/D \\
\hline $\begin{array}{l}\text { Andrich et al., } 2011 \\
{[29]^{\mathrm{a}}}\end{array}$ & $\mathrm{N} / \mathrm{D}$ & $\begin{array}{l}\text { Bulbar/membranous/ } \\
\text { prostatic }\end{array}$ & $\begin{array}{l}100 \% \text { bulbar, } \\
75 \% \text { bulbo- } \\
\text { prostatic }\end{array}$ & $\begin{array}{l}\text { Radiologically abnor- } \\
\text { mal }\end{array}$ & 42 & N/D \\
\hline $\begin{array}{l}\text { Webster et al., } 1990 \\
{[30]^{\mathrm{a}}}\end{array}$ & 20 & Membranous & N/D & $\begin{array}{l}\text { Need for any instru- } \\
\text { mentation }\end{array}$ & $\mathrm{N} / \mathrm{D}$ & N/D \\
\hline Shenfeld OZ, 2004 [45] & 8 & Membranous & $100 \%$ & $\begin{array}{l}\text { Need for any instru- } \\
\text { mentation }\end{array}$ & 27 & 2.8 \\
\hline $\begin{array}{l}\text { Kulkarni SB, } 2018 \\
{[46]^{\mathrm{a}}}\end{array}$ & 541 & Posterior & $79.13 \%$ & $\mathrm{~N} / \mathrm{D}$ & 68 & N/D \\
\hline
\end{tabular}

${ }^{a}$ Other techniques also described in the study 
$(n=2)[24,29]$ of studies represented the next most common definitions. $27 \%(n=6)$ of studies did not report the failure definition adopted for the data analysis. However, the definition utilised showed differing success rates. When failure was defined as a need for any instrumentation, success rates ranged from 68.7 to $100 \%$. The need for surgical intervention was associated with success rates of between 58 and $88 \%$. Radiological recurrence rate was reported as $0-25 \%$; however, this is a less useful measure, as re-intervention is also based on patients' symptoms rather than radiological abnormality in isolation.

\section{One-stage substitution urethroplasty}

Twenty-five studies (768 patients) described the use of onestage substitution urethroplasty with a variety of grafts and flaps (Table 2). It was used to treat anterior urethral strictures $(n=18)$, posterior strictures $(n=5)$ and panurethral strictures $(n=1)$. Three studies reporting anterior strictures focused on hypospadias cases with 5 studies not discussing the location of the urethroplasty. The mean length of the stricture was reported in six studies with the mean length reported between 4 and $8 \mathrm{~cm}[32-34,39,41,43]$.

The total success rate was between 18 and $100 \%$, at a mean follow-up between 4 and 82 months. Data on the success rate were missing from 5 of the studies. The most commonly utilised technique included the use of a buccal mucosal graft (BMG) in $80 \%$ of studies $(N=20)$. Three studies utilised a scrotal skin flap (scrotal inlay, Orandi flap, Barbagli patch) [20, 24, 29], with a further three using a penile skin (penile island flap) $[16,18,40]$. However, studies utilised a range of graft donor sites including abdominal skin [32], inner thigh skin [32], synthetic mesh [36], arm skin [32], post-auricular skin [20], lingual mucosa [24, 39], tunica vaginalis [38] and forearm free flap [19].

BMG grafts provided a success rate of $18-100 \%$ when used as a one-stage substitution in thirteen studies [11, 14, $25,29,31,33,34,36,37,41,43,47]$. The most commonly used definition for failure was the need for any instrumentation $(28 \%, n=7)$ with the success rate ranging from 68.8 to $88.2 \%$. The presence of any radiological abnormality $(12 \%$, $n=3$ ) provided a success rate of $60-100 \%$ with the need for surgical intervention $(16 \%, n=4)$ a success rate range of $18-100 \%$. Eight studies did not state the definition of failure. The largest cohort investigating BMG urethroplasty was seen in a study by Pandey et al. [34] which described 104 cases of anterior urethral strictures with a mean length of $8 \mathrm{~cm}$ and treated with a BMG ventral onlay urethroplasty with good success rates of $91.4 \%$ at 54 months.

Different graft sources provided success rates of $80 \%$ for skin grafts from the arm, $60 \%$ inner thigh skin graft, $50 \%$ for abdominal skin graft as reported by one study by
Sevinc et al. [32] and 60\% for scrotal skin graft reported by Andrich et al. [29].

Moreover, Vetterlein et al. [47] described success rates of one-stage BMG urethroplasty for anterior strictures in secondary (re-operation using technique different to the one used in primary intervention) and repeat cases (re-operation using the same technique as used in primary intervention). Secondary procedures were successful in $87.5 \%$ of cases and secondary cases provided success rates of $70.8 \%$. It was reported that a previous urethroplasty using any technique other than BMG urethroplasty had a significant negative impact on the outcome of the redo procedure.

\section{Two-stage substitution urethroplasty}

Twelve studies reported on 106 patients who had undergone a two-stage substitution urethroplasty procedure (Table 3 ). Five studies did not report the exact number of patients treated. It was used to treat anterior strictures in eight studies, posterior strictures in one and panurethral strictures in two studies. Three of the studies describing anterior strictures described only hypospadias cases and two did not report the exact site of the urethral stricture treated. Only one study described a mean stricture length of $8 \mathrm{~cm}$ (range $5-14 \mathrm{~cm}$ ) [48].

Eight studies utilised a BMG, with the remaining studies using post-auricular skin $(n=3)$, penile skin $(n=2)$, lingual mucosa $(n=1)$ and abdominal skin $(n=2)$ as a graft source. The total success rate ranged between 20 and $100 \%$ at a mean follow-up between 11.8 and 114-months in 12 studies $[5,11,15,19,20,25,35,36,40,42,44,48]$. Five studies failed to report the success rates specific to this technique. Failure was defined as the need for any instrumentation in 4 (success rate range was 50-82\%) and need for surgical intervention in 2 studies (success rate range of 20-100\%). One study used clinical evidence and increased post-void residual urine volumes as failure definition; the success rate reported was $86 \%$. Five studies did not define their success rates. Studies consisted of small cohorts with the biggest cohorts reported by Andrich et al. [42] and Morrison et al. with 49 and 27 cases, respectively [44].

\section{Stricture location, surgical procedures and their outcomes}

Urethral strictures were classified into penile, bulbar, bulboprostatic, bulbo-membranous, hypospadias and posterior urethral strictures. Two techniques were described for penile strictures: one-stage and two-stage substitution urethroplasty (stricture length ranged from 1 to $12 \mathrm{~cm}$ ). The success rates of $18-71.4 \%$, at a mean follow-up of 25.6-82 months, were achieved for penile strictures treated with one-stage BMG urethroplasty in two studies $[14,31]$. Poor success rate of 


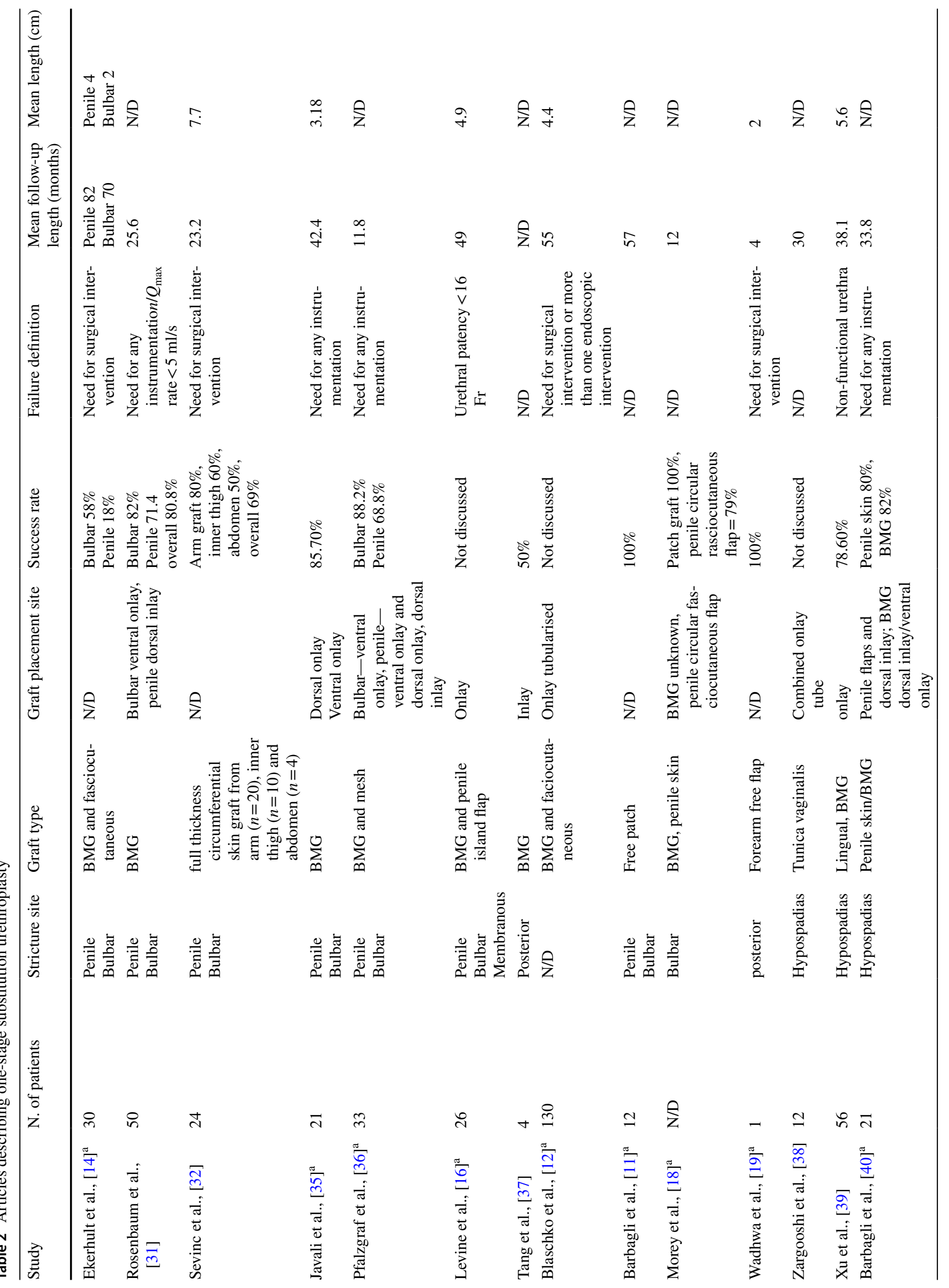


World Journal of Urology (2019) 37:1801-1815

1807

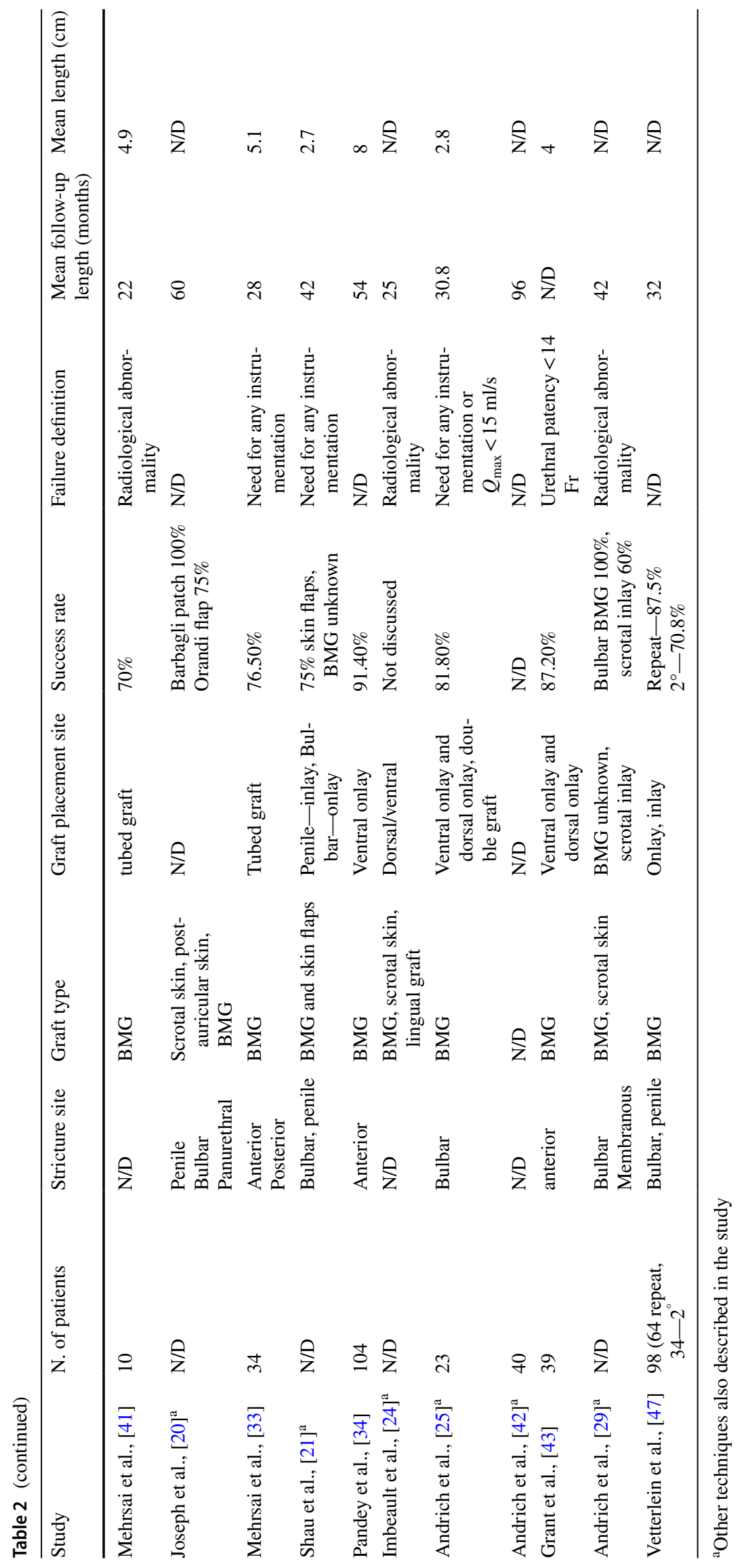

Springer 
Table 3 Articles describing two-stage substitution urethroplasty

\begin{tabular}{|c|c|c|c|c|c|c|c|c|}
\hline $\begin{array}{l}\text { Article first } \\
\text { author, year of } \\
\text { publication }\end{array}$ & N. of patients & Stricture site & Graft type & $\begin{array}{l}\text { Graft place- } \\
\text { ment }\end{array}$ & Success rate & $\begin{array}{l}\text { Failure defini- } \\
\text { tion }\end{array}$ & $\begin{array}{l}\text { Mean follow- } \\
\text { up length } \\
\text { (months) }\end{array}$ & $\begin{array}{l}\text { Mean } \\
\text { length } \\
(\mathrm{cm})\end{array}$ \\
\hline $\begin{array}{l}\text { Ekerhult et al., } \\
2016[14]^{\mathrm{a}}\end{array}$ & 5 & Penile & BMG & N/D & $20 \%$ & $\begin{array}{l}\text { need for surgical } \\
\text { intervention }\end{array}$ & 82 & 4 \\
\hline $\begin{array}{l}\text { Javali et al., } \\
2016[35]^{\mathrm{a}}\end{array}$ & N/D & Panurethral & lingual & $\begin{array}{l}\text { Bracka tech- } \\
\text { nique }\end{array}$ & N/D & $\begin{array}{l}\text { Need for any } \\
\text { instrumenta- } \\
\text { tion }\end{array}$ & 42.4 & 3.18 \\
\hline $\begin{array}{l}\text { Pfalzgraf et al., } \\
2014[36]^{\mathrm{a}}\end{array}$ & N/D & $\begin{array}{l}\text { Bulbar } \\
\text { Penile }\end{array}$ & $\mathrm{BMG}$ & N/D & N/D & $\begin{array}{l}\text { Need for any } \\
\text { instrumenta- } \\
\text { tion }\end{array}$ & 11.8 & N/D \\
\hline $\begin{array}{l}\text { Bhagat et al., } \\
2011[15]^{\mathrm{a}}\end{array}$ & N/D & N/D & $\mathrm{BMG}$ & Scrotal inlay & N/D & $\begin{array}{l}\text { Maximum } \\
\text { urinary } \\
\text { flow }<15 \mathrm{ml} / \mathrm{s}\end{array}$ & 60 & 3.7 \\
\hline $\begin{array}{l}\text { Barbagli et al., } \\
1996[11]^{\mathrm{a}}\end{array}$ & 3 & $\begin{array}{l}\text { Bulbar } \\
\text { penile }\end{array}$ & N/D & N/D & $100 \%$ & N/D & 57 & N/D \\
\hline $\begin{array}{l}\text { Wadhwa et al., } \\
1998\left[^{19}\right]^{\mathrm{a}}\end{array}$ & 3 & Posterior & N/D & N/D & $100 \%$ & $\begin{array}{l}\text { Need for surgical } \\
\text { intervention }\end{array}$ & 4 & 2 \\
\hline $\begin{array}{l}\text { Morrison et al., } \\
2018\left[^{4}\right]^{\mathrm{a}}\end{array}$ & 27 & Hypospadias & $\begin{array}{l}\text { BMG } \\
\text { Abdominal } \\
\text { skin } \\
\text { Post-auricular } \\
\text { skin }\end{array}$ & N/D & $100 \%$ for $\mathrm{BMG}$ & N/D & 114 & 7 \\
\hline $\begin{array}{l}\text { Barbagli et al., } \\
2006[40]^{\mathrm{a}}\end{array}$ & N/D & Hypospadias & $\begin{array}{l}\text { BMG/penile } \\
\text { skin }\end{array}$ & N/D & $\begin{array}{l}50 \% \text { for penile } \\
\text { skin, } 82 \% \text { for } \\
\text { BMG }\end{array}$ & $\begin{array}{l}\text { Need for any } \\
\text { instrumenta- } \\
\text { tion }\end{array}$ & 33.8 & N/D \\
\hline $\begin{array}{l}\text { Joseph et al., } \\
2002[20]^{\text {a }}\end{array}$ & N/D & $\begin{array}{l}\text { Penile } \\
\text { Bulbar } \\
\text { Panurethral }\end{array}$ & $\begin{array}{l}\text { BMG/post- } \\
\text { auricular skin }\end{array}$ & N/D & $\begin{array}{l}\text { 78.9\% for } \\
\text { BMG, } \\
\text { unknown for } \\
\text { other }\end{array}$ & N/D & 60 & N/D \\
\hline $\begin{array}{l}\text { Calvacanti } \\
\text { et al., } 2012 \\
{[25]^{\mathrm{a}}}\end{array}$ & 4 & $\begin{array}{l}\text { Bulbar } \\
\text { Penile }\end{array}$ & $\mathrm{BMG}$ & N/D & N/D & $\begin{array}{l}\text { Need for instru- } \\
\text { mentation of } \\
\text { maximum } \\
\text { urinary } \\
\text { flow }<15 \mathrm{ml} / \mathrm{s}\end{array}$ & 30.8 & 2.8 \\
\hline $\begin{array}{l}\text { Andrich et al., } \\
2005[42]^{\mathrm{a}}\end{array}$ & 49 & N/D & N/D & N/D & N/D & N/D & 96 & N/D \\
\hline $\begin{array}{c}\text { Meeks et al., } \\
2009 \text { [48] }\end{array}$ & 15 & Hypospadias & $\begin{array}{l}\text { BMG, abdomi- } \\
\text { nal skin, } \\
\text { penile skin, } \\
\text { posterior } \\
\text { auricular skin }\end{array}$ & N/D & $86 \%$ & $\begin{array}{l}\text { Clinical } \\
\text { evidence, } \\
\text { increased post- } \\
\text { void residual } \\
\text { volume on } \\
\text { USG }\end{array}$ & 23 & 8 \\
\hline
\end{tabular}

${ }^{\mathrm{a} O}$ Other techniques also described in the study

$20 \%$ was achieved for two-stage BMG urethroplasty in one study [31]. Twenty-six articles were excluded from this part of the review due to a lack of site-specific success rate data.

Five studies described redo-urethroplasty as a treatment for recurrent bulbar strictures (stricture length range $1-8 \mathrm{~cm}$ ). Techniques utilised included end-to-end anastomotic urethroplasty (four studies) and one-stage urethroplasty using a BMG (three studies) and fasciocutaneous penile flap (one study). Patients who received anastomotic urethroplasty achieved success in $58-100 \%$ of cases, at a mean follow-up of 12-82 months, as reported by four studies. The success rate of the substitution urethroplasty for bulbar strictures when using a BMG was $58-100 \%$, at a mean follow-up of 25.6-82 months) as described by four studies. One study reported the success rate of $79 \%$ at a mean follow-up of 12 months for the penile circular fasciocutaneous flap (Table 4).

Only the end-to-end anastomotic urethroplasty technique was reported for the treatment of bulbo-prostatic and bulbo-membranous urethral strictures in two studies and one study, respectively. Stricture lengths varied between 1.5 and $7 \mathrm{~cm}$ for bulbo-prostatic strictures and $1-3 \mathrm{~cm}$ for 
Table 4 The success rates of redo-urethroplasty for different urethral sites

\begin{tabular}{|c|c|c|c|c|c|}
\hline First author and date published & Urethral location & Technique used & Success rate $(\%)$ & N. of patients & $\begin{array}{l}\text { Mean } \\
\text { follow-up } \\
\text { (months) }\end{array}$ \\
\hline Ekelhult et al., 2016 [14] & Penile & One-stage BMG/fasciocutaneous & 18 & $\mathrm{n} / \mathrm{a}$ & 82 \\
\hline \multirow[t]{2}{*}{ Rosenbaum et., 2016 [31] } & \multirow[t]{2}{*}{ Penile } & One-stage dorsal inlay BMG & 71.40 & $\mathrm{n} / \mathrm{a}$ & 25.6 \\
\hline & & Two-stage BMG urethroplasty & 20 & $\mathrm{n} / \mathrm{a}$ & 25.6 \\
\hline \multirow[t]{2}{*}{ Ekelhult et al., 2016 [14] } & \multirow[t]{2}{*}{ Bulbar } & Anastomotic urethroplasty & 58 & $\mathrm{n} / \mathrm{a}$ & 70 \\
\hline & & One-stage BMG & 58 & $\mathrm{n} / \mathrm{a}$ & 70 \\
\hline Siegel et al., 2015 [17] & Bulbar & Anastomotic urethroplasty & 95 & 19 & 30.5 \\
\hline Rosenbaum et., 2016 [31] & Bulbar & One-stage ventral onlay BMG & 82 & $\mathrm{n} / \mathrm{a}$ & 25.6 \\
\hline \multirow[t]{2}{*}{ Andrich et al., 2011 [29] } & \multirow[t]{2}{*}{ Bulbar } & Anastomotic urethroplasty & 100 & $\mathrm{n} / \mathrm{a}$ & 42 \\
\hline & & One-stage bulbar BMG & 100 & $\mathrm{n} / \mathrm{a}$ & 42 \\
\hline \multirow[t]{3}{*}{ Morey et al., 1997 [18] } & \multirow[t]{3}{*}{ Bulbar } & Anastomotic urethroplasty & 100 & $\mathrm{n} / \mathrm{a}$ & 12 \\
\hline & & One-stage patch graft & 100 & $\mathrm{n} / \mathrm{a}$ & 12 \\
\hline & & $\begin{array}{l}\text { One-stage penile circular fasciocu- } \\
\text { taneous flap }\end{array}$ & 79 & $\mathrm{n} / \mathrm{a}$ & 12 \\
\hline \multirow[t]{5}{*}{ Barbagli et al., 2006 [40] } & \multirow[t]{5}{*}{ Hypospadias } & Anastomotic urethroplasty & 87 & $\mathrm{n} / \mathrm{a}$ & 33.8 \\
\hline & & One-stage BMG urethroplasty & 82 & $\mathrm{n} / \mathrm{a}$ & 33.8 \\
\hline & & One-stage penile skin flap & 80 & $\mathrm{n} / \mathrm{a}$ & 33.8 \\
\hline & & Two-stage penile skin & 50 & $\mathrm{n} / \mathrm{a}$ & 33.8 \\
\hline & & Two-stage BMG urethroplasty & 82 & $\mathrm{n} / \mathrm{a}$ & 33.8 \\
\hline Meeks et al., 2009 [48] & Hypospadias & Two-stage BMG urethroplasty & 86 & 12 & 23 \\
\hline Morrison et al., 2018 [44] & Hypospadias & Two-stage BMG urethroplasty & 100 & $\mathrm{n} / \mathrm{a}$ & 114 \\
\hline Pandey et al., 2017 [34] & Anterior & One-stage BMG ventral onlay & 91.40 & 104 & 54 \\
\hline Vetterlein et al., 2018 [47] & Anterior & One-stage BMG urethroplasty & $\begin{array}{l}\text { Repeat } 87.5 \\
2^{\circ}-70.8\end{array}$ & $\begin{array}{l}\text { Repeat } 64 \\
2^{\circ}-34\end{array}$ & 32 \\
\hline Kulkarni et al., 2015 [27] & Bulbo-membranous & Anastomotic urethroplasty & 93.30 & 15 & 18 \\
\hline Orabi et al., 2008 [23] & Posterior & Anastomotic urethroplasty & 97 & 51 & $\mathrm{n} / \mathrm{a}$ \\
\hline Pardeshi et al., 2016 [26] & Posterior & Anastomotic urethroplasty & 95.20 & 21 & $\mathrm{n} / \mathrm{a}$ \\
\hline Patrascoiu et al., 2012 [28] & Posterior & Anastomotic urethroplasty & 68.70 & 16 & 38 \\
\hline Tang et al., 2011 [37] & Posterior & one-stage BMG inlay & 50 & 4 & $\mathrm{n} / \mathrm{a}$ \\
\hline \multirow[t]{3}{*}{ Wadhwa et al., 1998 [19] } & \multirow[t]{3}{*}{ Posterior } & Anastomotic urethroplasty & 78.57 & 14 & 4 \\
\hline & & Forearm free flap & 100 & 1 & 4 \\
\hline & & Two-stage urethroplasty & 100 & 3 & 4 \\
\hline Gupta et al., 2008 [13] & Posterior & Anastomotic urethroplasty & 96.20 & 52 & 54 \\
\hline Shenfeld et al., 2004 [45] & Posterior & Anastomotic urethroplasty & 100 & 8 & 27 \\
\hline Kulkarni et al., 2018 [46] & Posterior & Anastomotic urethroplasty & 79.13 & 541 & 68 \\
\hline Andrich et al., 2011 [29] & Bulbo-prostatic & Anastomotic urethroplasty & 75 & $\mathrm{n} / \mathrm{a}$ & 42 \\
\hline Webster et al., 1990 [30] & Bulbo-prostatic & Anastomotic urethroplasty & 95 & 20 & $\mathrm{n} / \mathrm{a}$ \\
\hline
\end{tabular}

bulbo-membranous strictures. Success rates ranged from 75 to $95 \%[29,30]$ for bulbo-prostatic strictures and a $93.30 \%$ success rate was achieved for bulbo-membranous strictures in a single 15 patient case series [27].

Additionally, three studies described the success rates for different techniques used to treat the hypospadias-related strictures of the anterior urethra. The highest success rate was achieved for the two-stage BMG urethroplasty (success rates of $82-100 \%$ at mean follow-up of 23-114 months) as described by all three studies. Other urethroplasty techniques for hypospadias-related strictures were described by Barbagli et al. [40]; the anastomotic technique was successful in $87 \%$, followed by one-stage BMG urethroplasty which was successful in $82 \%$, one-stage penile skin urethroplasty with a success rate of $80 \%$ and two-stage penile skin urethroplasty with the success rate of only $50 \%$, all at the mean follow-up of 33.8 months. However, as the technique is usually chosen depending on the severity of the stricture, the success rates may be influenced by selection bias which may reduce the importance of these differences in results reported. 
Isolated posterior (membranous and prostatic urethra) strictures were treated utilising anastomotic, one-stage and two-stage redo urethroplasties. The anastomotic urethroplasty was reported as having successful outcomes in $68.7-100 \%$ of patients in seven studies. Only a single study with a small cohort of 4 cases was utilised for one-stage BMG urethroplasties which was successful in only $50 \%$ of cases (2/4 cases). Additionally, Wadhwa et al. [19] described the forearm flap graft as $100 \%$ successful in one patient and the two-stage substitution urethroplasty as $100 \%$ successful in three patients at 4 months follow-up.

\section{Complication rates and follow-up method post-redo-urethroplasty}

Twenty-nine studies were included in this part of the analysis and the results are summarised in Table 5. Six studies used only one method for follow-up. These included isolated uroflowmetry in two, standardised questionnaires in one and urethrography in three studies. Most commonly, three methods of follow-up were combined, as reported by eight of the studies. Ten studies used a multitier follow-up approach using questionnaires (study-specific questionnaires or AUA symptom score) or uroflowmetry as an initial screen, with cystoscopy or urethrography only conducted if obstructive symptoms were seen. The cutoff point of maximum urinary flow triggering secondary investigations was set at $12 \mathrm{ml} / \mathrm{s}$ in two studies [27, 40], $14 \mathrm{ml} / \mathrm{s}$ in two studies [11, 33] and $15 \mathrm{ml} / \mathrm{s}$ in three studies [25, 34, 49]. Overall, the most commonly used method of follow-up, both in isolation and as part of multitest approach, was urethrography, as reported in 18 studies.

Only four studies described details of the frequency of the follow-up regime. Uroflowmetry frequency varied at between 3 and 6 months in two studies $[32,35]$, with urethrography used one month post-operatively [45] and annually [31]. Average length of follow-up varied widely across studies between 4 and 114 months. The longest follow-up was 9.5 years reported by Morrison et al. [44]. Seven studies were followed up for less than 1 year, 14 for between 1 and 2 years, 6 for 2-3 years and 2 extended it to over 3 years. The most common complications described for each urethroplasty technique are summarised in Table 6.

Eight studies described the mean time to recurrence of urethral stricture after redo surgery with ranges from two to 50.2 months $[12,24,27,31,33,35,41,44]$. Six of these studies reported mean time to recurrence of less than 24 months [12, 24, 27, 31, 33, 41].

\section{Discussion}

Recurrent urethral strictures are a surgical challenge due to the increased complexity of the strictures due to scarring and poor tissue vascularity. Whilst DVIU offers a less invasive initial treatment modality, it is associated with a high recurrence rate. This systematic review offers an overview of the current evidence for redo-urethroplasty in recurrent strictures, comparing the outcomes using different surgical techniques and according to varying stricture location.

The evidence for the use of anastomotic end-to-end urethroplasty has been assessed in 22 studies. Overall success rates vary widely across studies at $0-100 \%$. When assessing its use to specific locations, anastomotic urethroplasty fared best when utilised in anterior bulbar and posterior recurrent strictures [11, 13, 14, 17-20, 23, 25, 27-29, 45, 46]. The success rates were reported as $58-100 \%$ and $68.7-100 \%$, respectively, for these cohorts of patients, with four studies reporting success rates of $100 \%$ in anterior bulbar strictures.

The success rates for these stricture locations were reported as 75-95\% [29, 30] and 93.30\% [27], respectively.

The evidence for the use of one-stage substitution urethroplasty has been assessed in 25 studies. The overall success rate varied across the studies at $18-100 \%$. The best results were obtained using the substitution urethroplasty technique for bulbar [14, 18, 25, 29, 31, 35, 36, 47] and hypospadiasrelated strictures $[39,40]$. The success rates were reported at $58-100 \%$ and $78.6-82 \%$, respectively, for these cohorts, with two studies reporting success rates of $100 \%$ in bulbar strictures. Conversely, the poorest outcomes were identified for posterior strictures with a success rate of only 50\%; however, this consisted of a single four-patient study [37]. Studies assessing both penile and bulbar urethral strictures [14, 31,36 ] achieved better results for the bulbar strictures with success rates of $18-71.40 \%$ and $58-88.2 \%$, respectively. The BMG demonstrated the best evidence base as a graft source for more complex stricture recurrences when compared with penile fasciocutaneous flap [18] and scrotal skin [29], with 10 studies reporting success rates of over $80 \%[18,25,29$, 31, 35-37, 40, 43, 47]. One-stage BMG urethroplasty was the most successful technique of all to treat penile strictures with a success rates of $71.40 \%$ [31].

Overall 12 studies assessed the use of two-stage substitution urethroplasty. The overall success rate varied across the studies at 20-100\%, with the best results obtained in hypospadias-related and posterior strictures. The success rates were reported at $82-100 \%$ [40, 44, 48] and 100\% [19], respectively, for these cohorts. However, the evidence for its use in posterior strictures is limited by a single small cohort study of three patients with a median stricture length of only $2 \mathrm{~cm}$. On the contrary, this technique demonstrated 


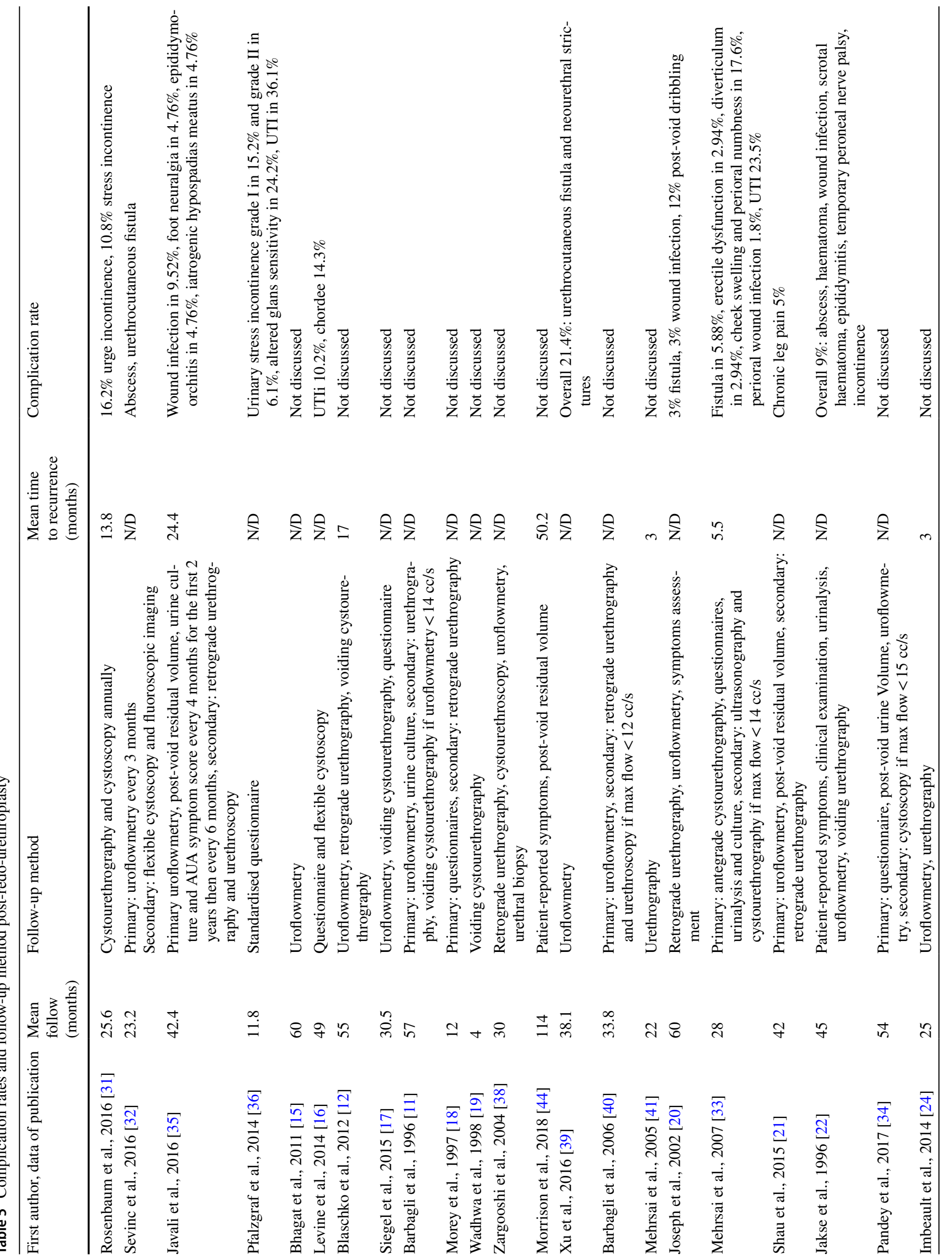


the poorest outcomes in penile strictures with a success rate of $20 \%$ (mean stricture length $4 \mathrm{~cm}$ ) [14]. However, results were quoted only for a small cohort consisting of five patients. The BMG was reported as a graft with the best evidence for two-stage substitution procedures and was superior to penile skin flap [40], with 3 studies reporting success rates of over $80 \%$ [40, 44, 48].

Based on the current best evidence and current guidelines identified, we have produced a suggested treatment algorithm for the management of recurrent urethral strictures (Fig. 2). Whilst the current evidence has demonstrated trends for treatment modalities according to the stricture location, it is important to consider that the identified evidence is limited in several factors.

All studies identified were level 4 evidence via case series or case-control studies only, with no randomised controlled studies identified. Furthermore, study cohorts were often retrospective and had limited follow-up with only 15 studies reporting over 40 participants. Formal risk of bias assessment conducted with use of the Quality Appraisal of Case Series Studies Checklist demonstrated that the majority of studies were prone to bias secondary to poor reporting on statistics and design. Most studies were single-centre retrospective case series with no formal statistical assessment, due to the small population size. Additionally, there was considerable study heterogeneity with broad aetiology inclusion criteria, with varying previous interventions and definitions of failures (Supplementary Table 1). Therefore, with this in mind it is important to consider the limitations of current trends in treatment and the widespread applicability of these results.

Finally, the choice of operation is based on the severity of the stricture. Single-stage procedures may be chosen for simple strictures, whereas more complex ones may be treated with two-stage surgery. This selection bias makes it virtually impossible to compare outcomes.

Understanding common complications for differing redo-urethroplasty techniques allows for patient-specific discussions pre-operatively (Table 6). The current literature demonstrates that common complications following end-toend anastomotic urethroplasty include erectile dysfunction, urinary incontinence and perineal haematoma. When considering one-stage BMG urethroplasty, postoperative UTI, altered glans sensitivity, and complications of graft harvesting including cheek swelling and perioral numbness were the most common complications described. When using other graft sources, urethrocutaneous fistula and abscess formation were seen to be more common. Finally, two-stage BMG urethroplasty was most commonly complicated by voiding symptoms, dysuria, BMG oral complications and fistula formation.

Stricture recurrence was seen at less than 24 months in six out of eight studies in this review, with the longest 
Table 6 Procedure-specific complication rates post-redo-urethroplasty

\begin{tabular}{|c|c|c|}
\hline Anastomotic urethroplasty & One-stage substitution urethroplasty & Two-stage substitution urethroplasty \\
\hline $\begin{array}{l}\text { De novo erectile dysfunction } 12.5-18.75 \% \text { [ } 22 \text {, } \\
28,45]\end{array}$ & UTI $(36.1 \%)[36]$ & Voiding symptoms and mild dysuria (21\%) [48] \\
\hline Urinary incontinence $(12.5 \%)[28,45]$ & Altered glans sensitivity $(24.2 \%)[36]$ & UTI (14\%) [48] \\
\hline Perineal haematoma $(12.5 \%)[28,45]$ & $\begin{array}{l}\text { Cheek swelling and perioral numbness } \\
(17.6 \%)[33]\end{array}$ & BMG oral complications (7\%) \\
\hline
\end{tabular}

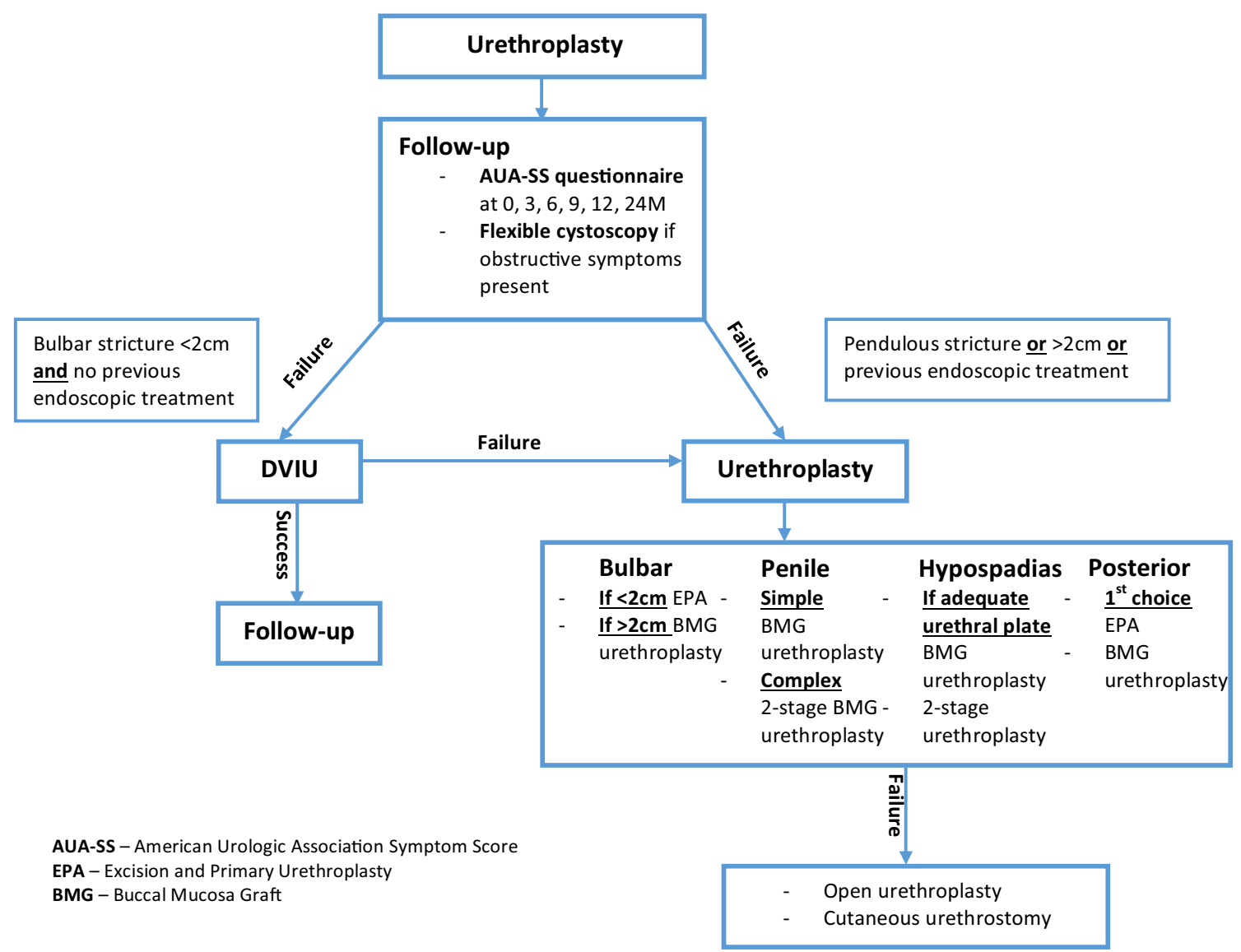

Fig. 2 Summary of the most effective redo-urethroplasty techniques identified according to the stricture location

time to recurrence of 50.2 months. Therefore, a standardised follow-up regime is required with an emphasis on this high-risk timeframe. Whilst the most cost-effective approach is difficult to establish from the current literature, previous evidence from a systematic review suggests a two-tier system to diagnose stricture recurrence [50]. A possible initial screening protocol could consist of the AUA-SS at every post-op visit, with flexible cystoscopy used as a second tier procedure if the obstructive symptoms are identified. Frequency of follow-up could be implemented on a 3-monthly basis initially with yearly follow-up after the first year (at $0 \mathrm{M}, 3 \mathrm{M}, 6 \mathrm{M}, 9 \mathrm{M}, 12 \mathrm{M}$ and $24 \mathrm{M}$ ).
Current evidence is reliant on level 4 studies. Therefore, it is clear that further work is required. Whilst technically difficult to conduct due to the variability in surgical technique for individual strictures, more randomised controlled and standardised studies are required. There is a need for prospective data comparing the success rates of specific procedures at different stricture locations, utilising standardised definitions of success rates. This should additionally be compared to less invasive techniques such as DVIU. Strict inclusion criteria with regard to previous intervention and definitions of failure are needed. This will ensure that the future management decisions are patient-specific and based on the objective evidence rather than an institution preference. 
We present the second systematic review on the outcomes of redo-urethroplasty, with a previous review of five studies, including paediatric cases conducted [51]. Success rates of between 35 and $85 \%$ out of a total of 212 redo-urethroplasty cases were identified. Through a broader search and inclusion criteria, we have been able to identify numerous further studies and, despite current paucity in high quality studies, are able to discuss trends in the evidence, with potential specific treatment modalities for strictures at different urethral sites. However, this review is not without its limitations. As mentioned previously, it is limited by the quality of the studies identified, with large heterogeneity and small cohort sizes meaning that results may not be applicable to all individual cases and no significant statistical pooling of results could be conducted. Additionally, this is a narrative systematic literature review leading to expert opinion. With all these limitations in mind, no definite conclusions may be drawn from the results. Even though the trends identified by this review are based on the best evidence available, we are uncertain whether suggested treatment modalities for different strictures guarantee the best possible outcomes.

\section{Conclusions}

The success rates of redo surgery after failed urethroplasty are comparable to primary surgery when the appropriate technique is used. This review identified the possible optimal urethroplasty technique for different urethral stricture locations based on the limited current evidence in the literature. Anastomotic urethroplasty fared best when utilised in bulbar and posterior strictures. Substitution urethroplasty was most successful when BMG was used as a graft source. The best results for one-stage BMG urethroplasty were achieved when treating bulbar and hypospadias-related strictures. Multistage BMG urethroplasty was the most successful technique for hypospadias-related and posterior strictures. Redo-urethroplasty treatment and the follow-up pathway algorithm were designed based on the current evidence and existing guidelines. However, the use of Quality Appraisal of Case Series Studies Checklist revealed high risk of bias in the poor quality of studies identified in this review. Thus, we are uncertain whether the trends discussed are the most effective interventions for management of redo urethral strictures. This review highlights the limited current evidence with small cohorts demonstrating the need for further investigation in this difficult to manage group of patients.
Author contributions SJ: protocol/project development, data collection and management, data analysis, manuscript writing. OB: protocol/ project development, data collection and management, data analysis, manuscript editing. RWR: manuscript editing. AM: manuscript editing. KA: protocol/project development, data collection and management, manuscript editing.

\section{Compliance with ethical standards}

\section{Conflict of interest No conflicts of interest to disclose.}

Open Access This article is distributed under the terms of the Creative Commons Attribution 4.0 International License (http://creativeco mmons.org/licenses/by/4.0/), which permits unrestricted use, distribution, and reproduction in any medium, provided you give appropriate credit to the original author(s) and the source, provide a link to the Creative Commons license, and indicate if changes were made.

\section{References}

1. Rosenbaum C, Schmid M, Ludwig T et al (2016) Redo buccal mucosa graft urethroplasty: success rate, oral morbidity and functional outcomes. BJU Int 118(5):797-803

2. Andrich DE, Dunglison N, Greenwell TJ et al (2003) The longterm results of urethroplasty. J Urol 170:90-92

3. Rapp DE, Chanduri K, Infusino G et al (2008) Internet survey of management trends of urethral strictures. Urol Int 80:287-290

4. Rosenbaum CM, Schmid M, Ludwig TA et al (2014) Internal urethrotomy in patients with recurrent urethral stricture after buccal mucosa graft urethroplasty. World J Urol 33:1337-1344

5. Wright JL, Wessells H, Nathens AB et al (2006) What is the most cost-effective treatment for 1 to 2-cm bulbar urethral strictures: societal approach using decision analysis. Urology 67:889-893

6. Rourke KF, Jordan GH (2005) Primary urethral reconstruction: the cost minimized approach to the bulbous urethral stricture. $\mathrm{J}$ Urol 173:1206-1210

7. Wessells H, Angermeier KW, Elliott SP et al (2017) Male urethral stricture. American Urological Association (AUA) Guideline. J Urol 197(1):182-190. https://doi.org/10.1016/j.juro.2016.07.087

8. Breyer BN, McAninch JW, Whitson JM et al (2010) Multivariate analysis of risk factors for long-term urethroplasty outcome. J Urol 183:613-617

9. Moher D, Liberati A, Tetzlaff J et al (2009) Preferred reporting items for systematic reviews and meta-analyses: the PRISMA statement. PLoS Med 6(7):e1000097

10. Institute of Health Economics (IHE) (2014) Quality appraisal of case series studies checklist. Institute of Health Economics, Edmonton. http://www.ihe.ca/research-programs/rmd/cssqac/ cssqac-about

11. Bargagli G, Selli C, Tosto A (1996) Reoperative surgery for recurrent strictures of the penile and bulbous urethra. J Urol 156:76-77

12. Blaschko S, McAninch J, Myers J, Schlomer B, Breyer B (2012) Repeat urethroplasty after failed urethral reconstruction: outcome analysis of 130 patients. J Urol 188(6):2260-2264

13. Gupta N, Mishra S, Dogra P et al (2008) Does a previous end-toend urethroplasty alter the results of redo end-to-end urethroplasty in patients with traumatic posterior urethral strictures? Int J Urol 15(10):885-888

14. Ekerhult T, Lindqvist K, Peeker R et al (2016) Outcomes of reintervention after failed urethroplasty. Scand J Urol 51(1):68-72 
15. Bhagat S, Gopalakrishnan G, Kumar S et al (2010) Redo-urethroplasty in pelvic fracture urethral distraction defect: an audit. World J Urol 29(1):97-101

16. Levine M, Kinnaird A, Rourke K (2014) Revision urethroplasty success is comparable to primary urethroplasty: a comparative analysis. Urology 84(4):928-933

17. Siegel J, Panda A, Tausch T et al (2015) Repeat excision and primary anastomotic urethroplasty for salvage of recurrent bulbar urethral stricture. J Urol 194(5):1316-1322

18. Morey A, Duckett C, McAninch J (1997) Failed anterior urethroplasty: guidelines for reconstruction. J Urol 158(4):1383-1387

19. Wadhwa S, Chahal R, Hemal A et al (1998) Management of obliterative posttraumatic posterior urethral strictures after failed initial urethroplasty. J Urol 159:1898-1902

20. Joseph J, Andrich D, Leach C et al (2002) Urethroplasty for refractory anterior urethral stricture. J Urol 167:127-129

21. Shau Y, Wu S, Kao C et al (2015) Management of complex urethral stricture disease: algorithm and experience from a single institute. Urol Sci 26(3):210-213

22. Jakse G, Marberger H (1986) Excisional repair of urethral stricture follow-up of 90 patients. Urology 27(3):233-236

23. Orabi S (2008) Re-do posterior urethroplasty: steps to achieve a success. J Urol 179(4):260

24. Imbeault A, Bugeja S, Frost A et al (2014) 82 The outcome of redo bulbar and membranous urethroplasty. Eur Urol Suppl 13(1):e82

25. Cavalcanti A, Rubinstein M (2012) 5 redo urethroplasty after failure of end-to-end anastomotic bulbar urethroplasty. J Urol 187(4):e2

26. Pardeshi A, Raghoji V (2016) 32 Technique of re-do posterior anastomotic urethroplasty for failed pelvic fracture urethral distraction defect. Indian J Urol Suppl 32(Suppl 1):S38-S165

27. Kulkarni S, Barbagli G, Joshi P et al (2015) Laparoscopic omentoplasty to support anastomotic urethroplasty in complex and redo pelvic fracture urethral defects. Urology 85(5):1200-1205

28. Patrascoiu S, Gingu C, Surcel C et al (2012) C167 redo anastomotic urethroplasties for pfudds. Eur Urol Suppl 11(4):122

29. Andrich D, Venkatesan K, Zacharakis E, Mundy AR (2011) The outcome of redo perineal urethroplasty The Institute of Urology, University College Hospital of LondonBJU Int suppl s1, 2011; 108: $1-16$

30. Webster G, Ramon J, Kreder K (1990) Salvage posterior urethroplasty after failed initial repair of pelvic fracture membranous urethral defects. J Urol 144(6):1370-1372

31. Rosenbaum C, Schmid M, Ludwig T et al (2016) Redo buccal mucosa graft urethroplasty: success rate, oral morbidity and functional outcomes. BJU Int 118(5):797-803

32. Sevinc C, Balaban M, Ozkaptan O et al (2016) Salvage urethroplasty using skin grafts for previously failed long-segment urethral strictures. Kaohsiung J Med Sci 32(9):464-468

33. Mehrsai A, Djaladat H, Salem S et al (2007) Outcome of buccal mucosal graft urethroplasty for long and repeated stricture repair. Urology 69(1):17-21

34. Pandey A, Borisenkov M, Barta-Kelemen A et al (2017) Re-do urethroplasty after unsuccessful urethral reconstruction with buccal mucosa graft. Eur Urol Suppl 16(3):e485
35. Javali T, Katti A, Nagaraj H (2016) Management of recurrent anterior urethral strictures following buccal mucosal graft-urethroplasty: a single center experience. Urol Ann 8(1):31

36. Pfalzgraf D, Kluth L, Reiss P et al (2013) Redo-urethroplasty: comparison of early functional results and quality of life in penile and bulbar strictures. World J Urol 32(5):1191-1197

37. Tang S, Kao C, Wu S et al (2012) Inlay buccal mucosal graft for reoperative posterior urethroplasty. Kaohsiung J Med Sci 28(4):220-224

38. Zargooshi J (2004) Tube-onlay-tube tunica vaginalis flap for proximal primary and reoperative adult hypospadias. J Urol 171(1):224-228

39. Xu Y, Li H, Fu Q et al (2016) One-stage dorsal lingual mucosal graft urethroplasty for the treatment of failed hypospadias repair. Asian J Androl 18(3):467

40. Barbagli G, De Angelis M, Palminteri E et al (2006) Failed hypospadias repair presenting in adults. Eur Urol 49(5):887-895

41. Mehrsai A, Djaladat H, Sina A et al (2005) Buccal mucosal graft in repeat urethroplasty. Urol J 2(4):206-210

42. Andrich D, Dalcum N, Holden F et al (2005) 748Restricture rates after revision urethroplasty. Eur Urol Suppl 4(3):189

43. Grant A, Ahmadi N, Wong J (2017) Outcomes of redo-urethroplasty in patients with prior failed urethral reconstruction surgery. BJU Int Suppl. https://doi.org/10.1111/bju.13751

44. Morrison C, Cinà D, Gonzalez C et al (2018) Surgical approaches and long-term outcomes in adults with complex reoperative hypospadias repair. J Urol 199(5):1296-1301

45. Shenfeld OZ, Gofrit ON, Gdor Y et al (2004) Anastomotic urethroplasty for failed previously treated membranous urethral rupture. Urology 63(5):837-840

46. Kulkarni SB, Surana S, Desai DJ et al (2018) Management of complex and redo cases of pelvic fracture urethral injuries. Asian J Urol 5(2):107-117

47. Vetterlein MW, Stahlberg J, Zumstein V et al (2018) The impact of surgical sequence on stricture recurrence after anterior onestage buccal mucosal graft urethroplasty: comparative effectiveness of initial, repeat, and secondary procedures. J Urol 200(6):1308-1314

48. Meeks JJ, Erickson BA, Gonzalez CM (2009) Staged reconstruction of long segment urethral strictures in men with previous paediatric hypospadias repair. J Urol 181(2):685-689

49. Myers JB, McAninch JW, Erickson BA (2012) Treatment of adults with complications from previous hypospadias surgery. J Urol 88(2):459-463

50. Meeks J, Erickson B, Granieri M et al (2009) Stricture recurrence after urethroplasty: a systematic review. J Urol 182(4):1266-1270

51. Blaschko SD, Breyer BN, McAninch JW (2014) Reoperative urethroplasty. A systematic review. Arch Esp Urol 67(1):138-141

Publisher's Note Springer Nature remains neutral with regard to jurisdictional claims in published maps and institutional affiliations. 